\title{
ЯЗЫКОЗНАНИЕ
}

\section{Парные глаголы с каузативным значением: семантические особенности (на материале бурятского языка)}

\section{Елена Александровна Дадуева ${ }^{1}$ Дарима Шагдуровна Харанутова}

${ }^{1}$ Бурятский государственный университет (д. 24, ул. Смолина, 670000 Улан-Удэ, Российская Федерация) кандидат филологических наук, докторант

iD 0000-0002-2562-7331.E-mail: edadueva@yandex.ru

\author{
2 Бурятский государственный университет (д. 24, ул. Смолина, 670000 Улан-Удэ, \\ Российская Федерация) \\ доктор филологических наук, доцент \\ (iD) 0000-0001-5692-5393. E-mail: dkharanutova@mail.ru
}

(C) КалмНЦ РАН, 2021

(C) Дадуева Е. А., Харанутова Д. Ш., 2021

Аннотация. Введение. В работе поднимаются проблемы семантики парных глаголов с каузативным значением в бурятском языке, на материале которого данная проблема ранее не рассматривалась. Основной целью исследования является выявление особенностей семантики парных каузативных глаголов бурятского языка. В задачи исследования входит: 1) выделить типы парных каузативных глаголов в бурятском языке; 2) определить степень участия и соотношения смыслового значения составляющих их компонентов при выведении общей семантики слова; 3) рассмотреть парные каузативные глаголы как особые способы выражения каузативной семантики. Maтериаль $u$ методы. Материалом исследования послужили примеры из художественных произведений, размещенных в Электронном корпусе бурятского языка. Использованы методы контекстного и дистрибутивного анализа. Результаты. Семантический анализ парных глаголов, демонстрирующих каузативные отношения, выявил, что в парных глаголах, образованных сочетанием некаузативный глагол + каузативный глагол, доминирующим компонентом оказывается каузативный глагол, что говорит о силе семантики каузации. Парные глаголы такого типа чаще всего выражают различные эмоциональные проявления воздействия, субъективную оценку. Авторы приходят к выводу, что парные глаголы, образованные на основе сочетаний каузативный глагол + каузативный глагол, отражают интенсивность воздействия, демонстрируют усиление значения каузации, так как при объединении синонимичных каузативных глаголов семы действия обобщаются и находятся как бы в одном фокусе внимания, что позволяет усилить выразительность парных глаголов, выдвигая на передний план их эмоциональную оценочность.

Ключевые слова: каузативность, каузативный глагол, каузативные парные глаголы, бурятский язык, словообразование, интенсификация 
Благодарность. Публикация подготовлена в рамках гранта на проведение инициативных научных исследований, поддержанного Бурятским государственным университетом имени Доржи Банзарова» (проект № 21-12-0502 «Категория каузативности в бурятском языке»).

Для цитирования: Дадуева Е. А., Харанутова Д. Ш. Парные глаголы с каузативным значением: семантические особенности (на материале бурятского языка) // Монголоведение. 2021. Т. 13. № 3. С. 590-599. DOI: 10.22162/2500-1523-2021-3-590-599

\title{
Buryat Paired Verbs with Causative Meaning: Semantic Features Reviewed
}

\section{Elena A. Dadueva ${ }^{1}$, Darima Sh. Kharanutova ${ }^{2}$}

${ }^{1}$ Banzarov Buryat State University (24, Smolin St., 670000 Ulan-Ude, Russian Federation) Cand. Sc. (Philology), Doctoral Student

(iD) 0000-0002-2562-7331. E-mail: edadueva@yandex.ru

${ }^{2}$ Banzarov Buryat State University (24, Smolin St., 670000 Ulan-Ude, Russian Federation) Dr. Sc. (Philology), Associate Professor

iD 0000-0001-5692-5393. E-mail: dkharanutova@mail.ru

(C) KalmSC RAS, 2021

(C) Dadueva E. A., Kharanutova D. Sh., 2021

\begin{abstract}
Introduction. The article discusses the semantics of paired causative verbs in the Buryat language, which has not been the subject of a special study yet. The aim was to study the semantic features of Buryat paired causative verbs by way of identifying: 1) the types of paired causative verbs, 2) the contribution of each semantic component of a verbt of its general semantics and their correlation, and 3) paired causative verbs as a special case in expressing causative semantics. Materials and methods. The data was collected from works of fiction in the Electronic Corpus of the Buryat language; contextual and distributive analysis were used as the primary methods of research. Results. Semantic analysis of paired causative verbs, illustrative of causative relationships in the linguistic picture of the Buryat world, indicated that in pairs of non-causative + causative verb the latter is a leading component, which demonstrates the power of causative semantics; the verbs of this type most often express various emotions associated with impact and subjective assessment. The other type are represented by pairs of synonymous causative verb + causative verb that are effective in expressing the intensity of the impact; with the semes of the synonymous verbs combined, the meaning of causation in such pairs is enhanced, and their expressiveness and emotionale valuation aspects come to the fore. Keywords: causativity, causative verb, paired verbs, Buryat language, word formation, evaluation, intensification

Acknowledgements. The reported study was granted by Banzarov Buryat State University, project no. 21-12-0502 'Category of Causativity in the Buryat Language'.

For citation: Dadueva E. A., Kharanutova D. Sh. Buryat Paired Verbs with Causative Meaning: Semantic Features Reviewed. Mongolian Studies (Elista). 2021; 13 (3): 590-599. (In Russ.). DOI: 10.22162/2500-1523-2021-3-590-599
\end{abstract}

\section{Введение}

Категория каузативности является универсальной категорией, отражающей понимание причинно-следственных отношений в языке носителями языка. Каузативность выражает отношения между двумя ситуациями, при которых одно 
событие становится возможным благодаря другой ситуации. В этих отношениях наблюдается цепочечная связь между событиями. Например: сушить белье белье сохнет. Надо сказать, что каузативность остается одной из самых не до конца исследованных категорий. До сих пор не существует единого определения каузативности, показывающего разнообразие каузативных конструкций в разных языках. По мнению М. Шибатани, дать определение каузативу нелегко, и если бы появилась такая возможность, то оно включало бы описание грамматических свойств всех конструкций, в которых реализуется каузативный показатель [Shibatani 1976: 1]. Расцвет изучения категории каузативности приходится на вторую половину прошлого столетия, однако до сих пор ее место в системе многих языков мира не определено, в том числе и в бурятском языке, который демонстрирует богатые средства репрезентации каузативных отношений на всех уровнях языковой системы [Дадуева 2011]. Категория каузативности в бурятском языке остается неясной, загадочной и во многом непонятной категорией, хотя в словарном составе бурятского языка имеется достаточное количество каузативных глаголов.

Среди каузативных глаголов бурятского языка выделяются парные каузативные глаголы. Какова семантика подобных глаголов и из чего она складывается? В данной работе поднимается проблема зависимости общей семантики парных глаголов со значением их компонентов на материале парных глаголов с каузативным значением.

Основной целью данной работы является выявление особенностей семантики парных каузативных глаголов в бурятском языке. В задачи исследования входит: 1) выделить типы парных каузативных глаголов в бурятском языке; 2) определить степень участия и соотношения смыслового значения составляющих их компонентов при выведении общей семантики слова; 3) рассмотреть парные каузативные глаголы как особые способы выражения каузативной семантики.

\section{Парные каузативные глаголы: определение, виды, структура}

В бурятском языке в каузативных конструкциях встречаются парные глаголы, являющиеся «копулятивными (совокупление) композитами» [Дырхеева и др. 2014: 17]. Парные слова состоят из компонентов, которые относятся к одной лексико-грамматической категории. Отметим, что к значимым свойствам парных слов относят смысловую монолитность и спаянность содержания [Дырхеева и др. 2014: 17]. Как отмечают исследователи, парные слова «представляют собой как бы переходные явления, находящиеся на стыке синтаксиса, лексики, а иногда и фразеологии» [Дырхеева и др. 2014: 18]. Действительно, парные слова нужно относить к сложносоставным (или составным) словам. Как указывается, способ образования парных слов - сложносоставной, который признается как разновидность сложения [Дырхеева и др. 2014: 20].

Следует отметить, что парные слова всегда являлись объектами особого внимания лингвистов, во всех общих и частных, конкретно-языковых изысканиях по грамматике и словообразованию монгольских языков проблема парных слов поднималась неоднократно [Дарбеева 1963; Дондуков 1966; Дырхеева и др. 2014; и др.]. Между тем, парные глаголы с каузативным значением специальным исследованиям в бурятском языке не подвергались. Безусловно, использование парных глаголов имеет свое предназначение в каузативной конструкции. 
В лингвистике к одной из основных проблем при изучении парных слов относят вопрос «о взаимоотношениях его компонентов, степени участия значений составных компонентов при выведении и возникновении общего значения» [Дырхеева и др. 2014: 28]. Г. А. Дырхеева выделяет две группы парных глаголов: «1) сочетания глаголов, имеющих хотя бы отдаленную семантическую близость между собой; 2) сочетания глаголов, не имеющих ничего общего между собой» [Дырхеева и др. 2014: 47].

Как подтверждает материал исследования, в бурятском языке парные каузативные глаголы также образуют две группы парных глаголов. Во-первых, каузативные парные глаголы образуются путем соединения каузативного и некаузативного глагола (к примеру, эрихэ энгэхэ 'просить, требовать' + 'обманываться в своих надеждах'). Во-вторых, каузативные парные глаголы образуются из сочетания двух каузативных глаголов (например, эбдэхэ һандаaха 'ломать, разбивать, разрушать, портить, нарушать, расстраивать' + 'разлаживать, портить, разбивать, разрушать, донашивать'). Так, каузативные парные глаголы по компонентному составу можно разделить на следующие группы:

1) каузативный глагол + некаузативный глагол;

2) каузативный глагол + каузативный глагол.

Как известно, «существует определенная семантическая закономерность в образовании парных слов, состав его компонентов ограничен смысловыми рамками, они должны быть либо синонимами, либо антонимами, либо обозначать понятия, относящиеся к одному или однородному классу предметов, явлений, действий» [Дырхеева и др. 2014: 29-30]. Компонентный состав парных каузативных глаголов составляют чаще всего глаголы-синонимы или глаголы с разным смысловым содержанием. Естественно, что парные каузативный глагол + некаузативный глагол не могут содержать компоненты-синонимы. Каузативные глаголы означают различные физические, эмоциональные или волевые воздействия на объекты. Некаузативные глаголы отличаются замкнутостью в субъекте.

Таким образом, парные каузативные глаголы можно распределить по следующим семантическим группам:

I. Каузативный глагол + некаузативный глагол:

1. Парные каузативные глаголы с компонентами с разным смысловым значением;

II. Каузативный глагол + каузативный глагол:

1. Парные каузативные глаголы с компонентами-синонимами;

2. Парные каузативные глаголы с компонентами с разным смысловым значением.

\section{Группа каузативный глагол + некаузативный глагол}

Рассмотрим данную группу на примере эрихэ энгэхэ. В результате объединения каузативного глагола эрихэ 'просить, требовать' с некаузативным глаголом энгэхэ ‘обманываться в своих надеждах’ появляется парный предикат с каузативным значением, который сохраняет значение каузативного глагола эрихэ 'просить, требовать'. Данные глаголы не являются синонимами, выражая совершенно разные значения. Объединение глаголов с различными смыслами, не имеющими ничего общего между собой, представляет довольно интересное явление в языке. Отметим, что при образовании парного глагола появляется 
значение негативной оценки ‘требовать, клянчить, попрошайничать' [Черемисов 1973: 772].

Как видим, доминирующим здесь является значение каузативного глагола эрихэ 'просить, требовать', присоединение к нему значения некаузативного глагола энгэхэ придало новообразованному глаголу эрихэ энгэхэ значение эмоциональной оценки воздействия с отрицательной эмоциональной семантикой. Данный парный глагол обозначает какое-то надоедливое, нудное прошение, назойливое требование, которое доставляет беспокойство и раздражение. Например, эмоционально-экспрессивное отношение прослеживается в конструкции:

$\begin{array}{rlllll}\text { (1) Ганса } & \text { юи } & \text { юумэ } & \text { эри-нэ } & \text { энгэ-нэ } & \text { бэшэ-ши } \\ \text { Один } & \text { ты } & \text { что-то } & \text { просить- } & \text { обманываться- } & \text { не-PART.2 } \\ & & & \text { PRS } & \text { PRS } & \end{array}$

'Не один ты постоянно что-то просишь' (Ч. Цыдендамбаев. Түрэл нютагһаа холо. 1958) [Бурятский корпус]

Еще одним примером является парный каузативный глагол аргадаха аядаха 'уговаривать, увещевать', образованный соединением каузативного глагола аргадаха 'уговаривать, упрашивать, молить' и некаузативного глагола аядаха 'приноравливаться, подлаживаться, подделываться, использовать случай'. Здесь также прослеживается появление оценочного компонента.

При соединении глаголов группы каузативный глагол + некаузативнылй глагол также наблюдается усиление значения воздействия, интенсификация каузативного воздействия. Например, һүрдэхэ айлгаха 'пугать, терроризировать'. Парный глагол образован в результате соединения некаузативного

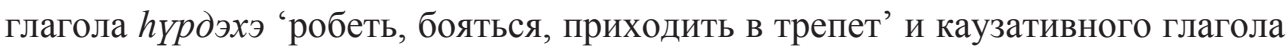

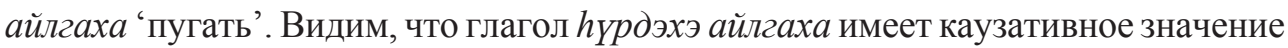
доминирующего компонента — каузативного глагола айлгаха 'пугать', только

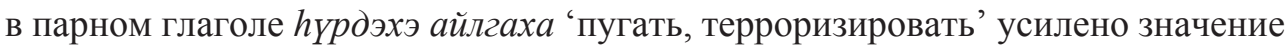
воздействия: не просто пугать, а терроризировать, т. е. производить достаточно сильное, отрицательное воздействие, угнетать.

Итак, из этих наблюдений вытекает несколько важных выводов: в парных каузативных глаголах, как и во всех парных словах, можно отметить наличие доминирующего компонента, и им чаще всего оказывается каузативный глагол. Исходя из этого, в парном глаголе семантика каузативности является настолько сильной, что практически всегда в таких сочетаниях сохраняется значение доминирующего компонента - каузативного глагола. Кроме того, примеры демонстрируют, что парные каузативные глаголы могут выражать эмоциональные проявления воздействия, их лексическое значение может быть представлено субъективно-эмоциональной оценкой.

Рассмотрим вторую группу парных каузативных глаголов, образованных соединением каузативный глагол + каузативный глагол. Оказывается, что в сочетании глаголов-синонимов один из компонентов всегда занимает доминирующее положение, его семантика оказывается сильнее, поэтому именно он будет выражать каузативное воздействие в обширном значении, второй же компонент - частное проявление этого воздействия, как, например, в слове xahaxa хороохо 'сокращать'. Глагол $x a h a x a$ 'лишать, изымать' обладает более 
широким значением воздействия, нежели глагол хороохо, который выражает частное значение воздействия 'убавлять, уменьшать'.

В парных каузативных глаголах оба компонента могут быть близки по смыслу, но различаться по объекту, на который оказывается воздействие, например в хахалха буталха 'раскалываться, разламываться' первый компонент означает разрушение чего-то твердого, прочного ('раскалываться, трескаться, ломаться, рваться'), но не на такие мелкие куски, как в значении слова буталха 'разбивать вдребезги, разваливать, рассыпать' Получается, что такие парные каузативные глаголы обозначают сразу два воздействия на один и тот же каузируемый объект. Объект испытывает на себе действия, названные обоими каузативными глаголами, что также свидетельствует об усилении значения воздействия, об его интенсификации. На наш взгляд, парные глаголы, состоящие из синонимов, интенсифицируют значение воздействия, усиливают значение каузации.

Далее рассмотрим слово эбдэхэ һандааха 'разрушать'. Компоненты парного глагола: эбдэхэ 'ломать, разбивать, разрушать, портить, нарушать, расстраивать', hандаaxa 'разлаживать, портить, разбивать, разрушать, донашивать'. Без сомнения, соединение значений синонимичных каузативных глаголов приводит к интенсификации значения глагола эбдэхэ, усилению значения каузации. Например:

(2) Эбдэ-бэ ломать-PST.3.SG һанд-аа-ба

разрушать-CAUS.PST.3.SG заншал-ьл-мнай обычай-ACC-POSS.1.PL

‘Он разрушил наши обычаи’ (Ц. Шагжин. Сахилгаата һүни. 1987) [Бурятский корпус]

В данной конструкции парные глаголы эбдэхэ hандаaха выражают достаточно сильное проявление действия: обычаи разрушены до такой степени, что последствия «ломки» устоев вызывают негодование говорящих, что прослеживается в следующем контексте:

$\begin{array}{llllll}\text { Нютаг } & \text { арад } & \text { зон-доо } & \text { нёлбо-бо, } & \text { наадал-ба, } & \text { баһа-ба } \\ \text { Родной-А } & \text { народ } & \text { народ-DAT. } & \text { плевать- } & \text { насмехаться- } & \text { издеваться- } \\ & & \text { POSS } & \text { PST.3.SG } & \text { PST.3.SG } & \text { PST.3.SG }\end{array}$

‘Он наплевал на свой народ и издевается над ним' (Ц. Шагжин. Сахилгаата һүни. 1987) [Бурятский корпус]

Парный глагол с каузативным значением, компонентами которого являются абсолютные синонимы зобоохо и туляаха 'мучить', наблюдаем в следующей конструкции:

$\begin{array}{lllllll}\text { (4) Тэрэгуйдэ } & \text { энэ } & \text { бузар } & \text { ТүшэгуҮн } & \text { шам-айе } & \text { зобоо-хо } & \text { туляаха } \\ \text { Иначе } & \text { этот мерзкий-А } & \text { Тушэгун- } & \text { ты-ACC } & \text { мучить- } & \text { мучить- } \\ & & & \text { NOM } & & \text { FUT.3.SG } & \text { PC }\end{array}$

'В противном случае этот мерзкий Тушэгун тебя замучает' (Б. Санжин, Б. Дандарон. Заяанай зам. 1966) [Бурятский корпус].

Глагол туляаха зобоохо означает высшую степень проявления воздействия.

Та же ситуация прослеживается и в парных союзах глаголов волевого воздействия, например, баалаха баадхаха 'заставлять', зааха захиха 'указывать, 
показывать' и т. п. Сочетание двух подобных глаголов, естественно, интенсифицирует значение волевого воздействия.

Парные синонимичные глаголы отличаются не только оттенками значения, но и характеристиками каузируемого объекта. Так, например, в парном каузативном глаголе харюулха бусааха 'а) возвращать обратно; б) отплачивать, компенсировать’ компонент харюулха ‘отправлять назад, возвращать, отпускать обратно’ используется в отношении и к человеку, и к вещам, а второй глагол бусааха 'возвращать, отдавать обратно' чаще имеет отношение только к вещам. В парном виде они используются в более широком значении «возвращать кого-либо, что-либо, компенсировать, отплачивать».

Глаголы хамhалсаха 'оказывать помощь, помогать' и туһалалсаха 'приносить пользу друг другу’, используемые в ассистивных конструкциях, которые обозначают социативную каузацию, значение помощи в бурятском языке, могут употребляться и как парные, общим для двух компонентов является значение «оказание помощи», однако если один из компонентов туһалсаха предполагает помощь в положительном деле, то второй компонент, глагол $x a$ haлcaxa, предполагает помощь и в неблаговидном деянии [Дырхеева и др. 2014: 40]. Парный же глагол имеет более широкое значение, myhaлcaха хамhалсаха означает 'всячески помогать друг другу', помогать в любом деле. И, безусловно, конструкции с такими парными глаголами отражают положительную оценку. Например:

(5) Гэр-ээ бари-ха-да-мни Бадма ехэ туһалса-ба хамһалса-ба

Дом-POSS строить-PC.FUT- Бадма- очень помогать- помогатьDAT-POSS.1.SG NOM PST.3.SG PST.3.SG

'Когда я строил дом, Бадма всячески мне помогал'

Объединение усилий синонимичных глаголов приводит к интенсификации семантики воздействия. Похожие действия объединяются в один парный глагол, действия обобщаются и находятся как бы в одном фокусе внимания, усиливая значение каузации. Концентрация действий в одном фокусе внимания позволяет усилить выразительность, выдвигая на передний план эмоциональную оценочность. Как, например, парный глагол эсээхэ сусааха 'изнурять, измучивать' демонстрирует большую степень концентрации воздействия, усиление выразительности, нежели глаголы-компоненты эсээхэ 'утомлять' и сусаaха 'утомлять' каждый по отдельности.

Таким образом, каузативные парные глаголы, образованные глаголамисинонимами, реализуют более глубокий, концентрированный, обобщенный, выразительно-эмоциональный смысл.

Парные глаголы, состоящие из слов с разным смысловым содержанием, чаще всего приобретают общее значение, которое принадлежало одному из компонентов пары: шалааха зобоохо 'мучить'. Так, глагол шалааха означает 'заставлять томиться от бездействия, оставлять в бездействии', а глагол зобоохо - 'причинять страдания, мучить, терзать, беспокоить, тревожить'. Общее значение парного каузативного глагола принадлежит глаголу зобоохо. Например:

\footnotetext{
${ }^{1}$ Примеры, где не указаны источники, носят искусственный характер.
} 
(6) Юун-дэ

Что-DAT

\begin{abstract}
эдээн-иие
\end{abstract}
шала-гаа

зобоо-гоо

хүм-ии

‘Почему ты их мучаешь?' (Х. Намсараев. Эдиршүүд. 1949) [Бурятский корпус].

\title{
Группа каузативный глагол + некаузативный глагол
}

Рассмотрим парные глаголы, образованные в результате сложения каузативных глаголов с совершенно разным смыслом, например, хардаха буридаха, хардаха гурдэхэ 'незаслуженно чернить, позорить; обливать грязью'. Парный каузативный глагол хардаха гүрдэхэ, каузативные глаголы хардаха 'клеветать, оговаривать; злостно обвинять' и гүрдэхэ '1) ловить вершей (рыбу); 2) (перен.) оговаривать кого-л., клеветать на кого-л.; провоцировать кого-л. на что-л.' не являются синонимами, но в процессе образования нового слова у второго компонента активизируется переносное значение 'оговаривать кого-л., клеветать на кого-л.; провоцировать кого-л. на что-л.', за счет чего в парном глаголе усиливается оценочное значение «незаслуженно оговаривать, чернить, позорить». Образованный парный глагол хардаха гурдэхэ 'незаслуженно чернить, позорить; обливать грязью’ получает высшую степень отрицательной оценки воздействия. Например:

(7)

$\begin{array}{ll}\text { Tэрээн-эй } & \text { забһар-аар } \\ \text { Tот-GEN } & \text { промежуток- } \\ & \text { INS } \\ \text { гэ-эд, } & \text { нам-айе } \\ \text { сказать- } & \text { я-ACC } \\ \text { CV } & \end{array}$

$$
\text { Үнэхөөрөө }
$$

\section{Гомбо}

хоёр

ниилэ-хэ Должон

'Действительно, в то самое время Гомбо и Должон, желая соединиться, позорят меня’ (Ц. Дон. Брынзын санха.1935) [Бурятский корпус].

Еще один пример парных каузативных глаголов, представляющих компоненты с разным смысловым значением, наблюдается в конструкции:

(8)

$\begin{array}{llr}\text { Элдэбын } & \text { муу } & \text { газар-аар } \\ \text { Всякий-А } & \text { плохой-А } & \text { земля-INS }\end{array}$

$\begin{array}{ll}\text { дахуул-жа, } & \text { эсээ-бэ } \\ \text { вести за } & \text { утомлять- } \\ \text { собой-CV } & \text { PST.3.SG }\end{array}$

зобоо-бо замучитьPST.3.SG

‘Замучил, поведя за собой по плохой земле' (Б. Мунгонов. Хара һалхин. 1971) [Бурятский корпус].

В данной конструкции соединяются каузативный глагол эсээхэ 'утомлять' и каузативный глагол зобоохо 'мучить'. Значение глагола зобоохо оказывается доминирующим.

В бурятском языке встречаются глаголы, довольно часто участвующие в парных глаголах как одни из компонентов. Например, каузативный глагол xamaxa 'прижимать, придавливать, притискивать, припирать' наблюдаем в сочетаниях с несинонимичными каузативными глаголами хаaхa 'закрыть', зобоохо 'мучить', баалаха 'заставлять', туляаха 'мучить'. Парные глаголы хашаха хааха, хашаха туляаха, хашаха зобоохо, хашаха баалаха имеют значение 'мытарить, преследовать'. 
Образование парных глаголов из несинонимичных глаголов также интересно тем, что оба глагола могут утрачивать свое основное значение. К примеру, глагол алаха 'убивать' демонстрирует продуктивность при образовании новых парных слов с каузативным значением. Например, aлаха эдихэ 'мучить, изводить' (эдихэ 'кушать, есть'), алаха түлэхэ 'донимать' (түлэхэ 'платить, оплачивать, топить, растапливать'), алаха шараха 'избивать, пытать' (щараха 'жарить'), алаха хюдаха 'уничтожать, стереть с лица земли' (хюдаха 'уничтожать, истреблять') и т. п. Отметим, что в данных примерах глагол алаха выступает в функции интенсификатора значения парного сочетания. Такие сочетания достаточно выразительны и выражают отрицательную оценку.

Заметим, в системе каузативных конструкций в бурятском языке довольно очевидна роль оценки. Бурятские каузативные конструкции обладают большим потенциалом в плане оценки каузативных связей говорящим. Если исходить из того, что именно оценка является одним из способов отражения языковой картины мира носителя языка, то, безусловно, использование каузативных парных глаголов в каузативных конструкциях иллюстрирует их высокий оценочный потенциал.

\section{Заключение}

В бурятском языке одним из интересных компонентов каузативной конструкции являются парные каузативные глаголы, представляющие особые способы выражения каузативной семантики и оценки.

Так, парные каузативные глаголы, образованные из сочетания некаузативный + каузативныц глагол, выражают различные эмоциональные проявления воздействия, субъективную оценку. Доминирующим компонентом в них оказывается каузативный глагол. Использование парных синонимичных каузативных глаголов отражает интенсивность воздействия. Часто в бурятском языке похожие действия объединяются в один парный глагол, действия обобщаются и находятся как бы в одном фокусе внимания, усиливая значение каузации. Концентрация действий в одном фокусе внимания позволяет усилить выразительность, выдвигая на передний план эмоциональную оценочность.

Соединение двух, на первый взгляд, совершенно разных слов происходит «путем установления отношений между двумя концептами и пропозициями в сознании носителя языка» [Дырхеева и др. 2014: 93]. Проблема развития процесса изменения концептов, их слияния является одной из насущных проблем бурятоведения, ведь при объединении слов в одно целое носитель языка выбирает именно эти два слова. Выбор обусловлен, безусловно, тем, что говорящий преследует определенные цели, чтобы наилучшим образом выразить свою мысль. В нашем случае при помощи парных глаголов актуализируются каузативные значения, которые дополняются экспрессивно-эмоциональным содержанием.

\section{Условные обозначения грамматических значений в глоссах}

А - прилагательное

ACC - винительный падеж

CAUS - каузативный глагол

$\mathrm{CV}$ - деепричастие

DAT — дательный падеж

GEN - родительный падеж 
IMP - повелительное наклонение

INS - инструментальный падеж

NOM - именительный падеж

PART - частица

PL — множественое число

PC.FUT - причастие будущего времени

POSS - лично-притяжательная частица

PRS - настоящее время

PST - прошедшее время

$\mathrm{SG}$ - единственное число

$1-1$-е лицо

2 - 2-е лицо

3 - 3 -е лицо

\section{Источники}

Бурятский корпус - Бурятский корпус [электронный ресурc] // URL: http://web-corpora. net/BuryatCorpus/search/?interface_language=ru (дата обращения: 03.08.2021).

\section{Sources}

Buryat Language Corpus. Available at: http://web-corpora.net/BuryatCorpus/search/?interface language=ru (accessed: August 3, 2021). (In Bur.)

\section{Литература}

Дадуева 2011 - Дадуева Е. А. Функционально-семантическая категория каузативности в русском и бурятском языках. Улан-Удэ: Изд-во Бур. гос. ун-та, 2011. 128 с.

Дарбеева 1963 - Дарбеева A. А. К вопросу о парных словах в бурятском языке // Вопросы литературного бурятского языка. Улан-Удэ: [б. и.], 1963. С. 15-27.

Дондуков 1966 - Дондуков У.-Ж. Ш. О парном словообразовании в монгольских языках // Штудиа Монголика. Улан-Батор: АН МНР, 1966. С. 54-61.

Дырхеева и др. 2014 - Дырхеева Г. А., Харанутова Д. Ш., Бардамова Е. А. Парные слова и парное словообразование в бурятском языке. Улан-Удэ: Изд-во БНЦ СО PAH, 2014. 208 c.

Черемисов 1973 - Черемисов К. М. Бурятско-русский словарь. М.: Сов. энциклопедия, $1973.804 \mathrm{c}$.

Shibatani 1976 - Shibatani M. The Grammar of Causative Constructions; a Conspectus // Syntax and Semantics. New York: Academic Press, 1976. Vol. 6. Pp. 1-40.

\section{References}

Cheremisov K. M. Buryat-Russian Dictionary. Moscow: Sovetskaya Entsiklopediya, 1973. 804 p. (In Bur. and Russ.)

Dadueva E. A. Functional-Semantic Category of Causativity in Russian and Buryat. Ulan-Ude: Buryat State University, 2011. 128 p. (In Russ.)

Darbeeva A. A. Revisiting Buryat paired lexemes. In: Issues of Standard Buryat. Ulan-Ude, 1963. Pp. 15-27. (In Russ.)

Dondukov U.-Zh. Sh. Formation patterns of paired lexemes in Mongolic languages. In: Studia Mongolica. Ulaanbaatar: MPR Academy of Sciences, 1966. Pp. 54-61. (In Russ.)

Dyrkheeva G. A., Kharanutova D. Sh., Bardamova E. A. Paired Lexemes and Related Buryat Word-Formation Patterns. Ulan-Ude: Buryat Scientific Center (SB RAS), 2014. 208 p. (In Russ.)

Shibatani M. The grammar of causative constructions: A conspectus. In: Syntax and Semantics. New York: Academic Press, 1976. Vol. 6. Pp. 1-40. (In Eng.) 